\title{
The SAFE or SORRY? programme. Part II: Effect on preventive care ${ }^{\text {th }}$
}

\author{
Betsie G.I. van Gaal ${ }^{\mathrm{a}, *}$, Lisette Schoonhoven ${ }^{\mathrm{a}}$, Joke A.J. Mintjes ${ }^{\mathrm{b}, \mathrm{c}}$, George F. Borm ${ }^{\mathrm{d}}$, \\ Raymond T.C.M. Koopmans ${ }^{\mathrm{e}}$, Theo van Achterberg ${ }^{\mathrm{a}}$
}

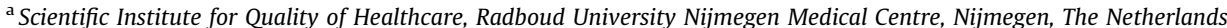

${ }^{\mathrm{b}}$ Faculty of Health and Social Studies, HAN University of Applied Sciences, Nijmegen, The Netherlands

${ }^{\mathrm{c}}$ Netherlands Centre for Excellence in Nursing, Utrecht, The Netherlands

${ }^{\mathrm{d}}$ Department of Epidemiology, Biostatistics and HTA, Radboud University Nijmegen Medical Centre, Nijmegen, The Netherlands

e Department of Primary and Community Care, Centre for Family Medicine, Geriatric Care and Public Health,

Radboud University Nijmegen Medical Centre, Nijmegen, The Netherlands

\section{A R T I C L E I N F O}

Keywords:

Guidelines

Hospitals

Implementation

Long-term care

Multicentre studies

Process indicators

\begin{abstract}
A B S T R A C T
Background: Patient care guidelines are usually implemented one at a time, yet patients are at risk for multiple, often preventable, adverse events simultaneously.

Objective: The SAFE or SORRY? programme targeted three adverse events (pressure ulcers, urinary tract infections and falls) and was successful in reducing the incidence of these events. This article explores the process of change and describes the effect on the preventive care given.

Design: Separate data on preventive care were collected along the cluster randomised trial, which was conducted between September 2006 and November 2008.

Settings: Ten hospital wards and ten nursing home wards.

Participants: We monitored nursing care given to adult patients with an expected length of stay of at least five days.

Methods: The SAFE or SORRY? programme consisted of the essential recommendations of guidelines for pressure ulcers, urinary tract infections and falls. A multifaceted implementation strategy was used to implement this multiple guidelines programme. Data on preventive care given to patients were collected in line with these guidelines and the difference between the intervention and the usual care group at follow-up was analysed. Results: The study showed no overall difference in preventive pressure ulcer measures between the intervention and the usual care group in hospitals (estimate $=6 \%, \mathrm{CI}:-7-19$ ) and nursing homes (estimate $=4 \%, \mathrm{CI}$ : $-5-13$ ). For urinary tract infections, even statistically significantly fewer hospital patients at risk received preventive care (estimate $=19 \%, \mathrm{CI}: 17-21$ ). For falls in hospitals and nursing homes, no more patients at risk received preventive care.

Conclusion: Though the SAFE OR SORRY? programme effectively reduced the number of adverse events, an increase in preventive care given to patients at risk was not demonstrated. These results seem to emphasise the difficulties in measuring the compliance to guidelines. More research is needed to explore the possibilities for measuring the implementation of multiple guidelines using process indicators.
\end{abstract}

(c) 2011 Elsevier Ltd. All rights reserved.

\footnotetext{
Trial registration: clinicaltrials.gov, number NCT00365430.

* Corresponding author at: Scientific Institute for Quality of Healthcare, Radboud University Nijmegen Medical Centre, 114 IQ Healthcare, PO Box 9101, 6500 HB Nijmegen, The Netherlands. Tel.: +31 24 3619326; fax: +31243540166.

E-mail address: b.vangaal@iq.umcn.nl (Betsie G.I.van Gaal).
}

\section{What is already known about the topic?}

- The incidence of adverse events could be reduced by using evidence-based guidelines.

- There is a large number of relevant guidelines that need to be implemented. 
- The SAFE OR SORRY? programme aimed at implementing three guidelines simultaneously and successfully reduced the incidence of adverse events.

\section{What this paper adds}

- Though the SAFE OR SORRY? programme results in fewer adverse events, more adequate preventive care could not be measured.

- Measuring the effect of the implementation of guidelines on prevention is complex.

- More research is needed to develop process indicators for monitoring preventive care.

\section{Introduction}

In a recent study, we developed a comprehensive patient safety programme (SAFE or SORRY?) that allows organisations to implement multiple guidelines simultaneously. We designed a cluster randomised trial to test the effect of this programme in hospitals and nursing homes. The programme was developed for three frequently occurring nursing care related adverse events: pressure ulcers, urinary tract infections and falls. The aim of the trial was to test whether the programme resulted in a lower incidence of these three adverse events in hospitals and nursing homes. In a separate paper (Part I), we described the results on this primary outcome (Van Gaal et al., 2011).
However, to understand the process of change, we undertook a study with separate data collection methods alongside the main trial. The aim of this study was to test if effects on the main outcome (incidence of adverse events) coincided with favourable effects on preventive care.

\section{Methods}

The design and setting of the cluster randomised trial, which was conducted between September 2006 and November 2008, has been described in Part I (Van Gaal et al., 2011). After the three-month baseline period the SAFE OR SORRY? programme was implemented, followed by a nine-month follow-up period. As described in Part I, ten wards from four hospitals and ten wards from six nursing homes were stratified for institute and ward type and then randomised to intervention or usual care group. During baseline and follow-up, patients ( $\geq 18$ years) with an expected length of stay of at least five days, were asked to participate. We copied the trial profile of the study in this article (Fig. 1) (Van Gaal et al., 2011). The intervention, the patient safety programme, has also been described in Part I of this study, and essentially consisted of education, patient involvement, and feedback on process and outcome indicators to facilitate the implementation of guidelines on the prevention of pressure ulcers, urinary tract infections and falls, simultaneously.
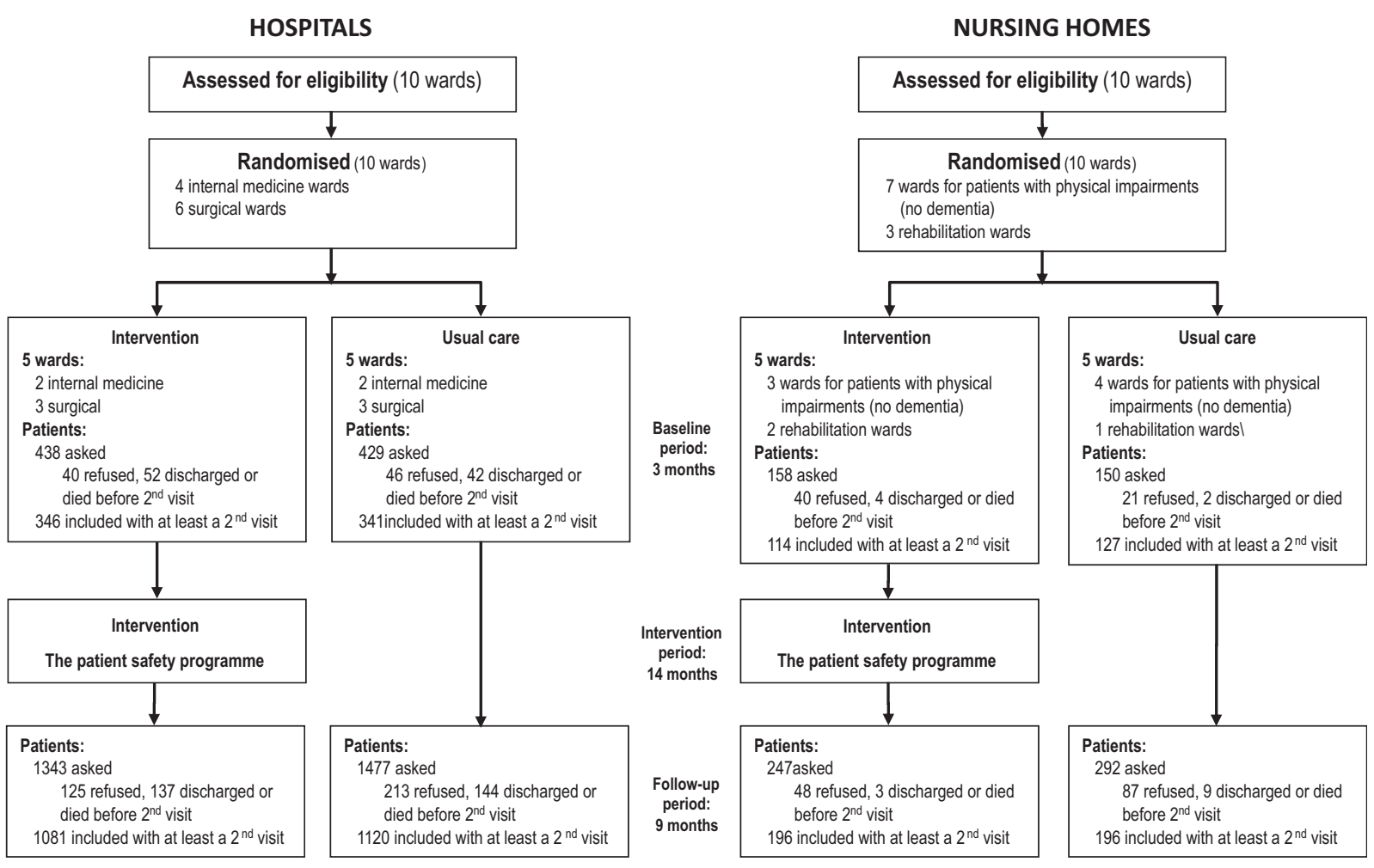

Fig. 1. Trial profile of Part I of this study. 


\subsection{Process measures}

The process of change was assessed with process indicators: the percentages of patients at risk who received preventive care according to the guidelines.

Patients at risk for pressure ulcers were defined as patients with mobility or activity impairments according to the Braden subscales "mobility" or "activity" (score less than 3) and/or were at risk according to a risk assessment tool. In hospitals, we used the PrePURSE scale (score more than 19) (Schoonhoven et al., 2006) and in nursing homes we used the Braden scale (score less than 18) (Braden and Bergstrom, 1994). Preventive care practices are shown in Fig. 2. We considered adequate preventive pressure ulcer care to have been provided if each of these had been met for patients identified at risk for pressure ulcers (Defloor et al., 2005; Dutch Association of Nursing Home Physicians (NVVA), 2003; Dutch Institute for Healthcare Improvement [CBO], 2002).

Hospital patients were defined as being at risk for a urinary tract infection if they had at least one of the following four risk factors: (1) an indwelling catheter or an indwelling catheter less than one week before, (2) fecal incontinence, (3) urinary retention or (4) a urinary tract infection in the last two years (Dutch Association of Nursing Home Physicians (NVVA), 2006; Dutch Working Party on Infection Prevention (WIP), 2005). Nursing home patients at risk for a urinary tract infection included all nursing home patients (Dutch Association of Nursing Home Physicians (NVVA), 2006). We considered adequate preventive urinary tract infection care to have been provided if each of these had been met for patients identified at risk for urinary tract infections (Fig. 2) (Dutch
Association of Nursing Home Physicians (NVVA), 2006; Dutch Working Party on Infection Prevention (WIP), 2005).

We used the STRATIFY tool (score more than 1) (Oliver et al., 1997) to identify hospital patients at risk for falls. In nursing homes, all patients were considered to be at risk for falls, except those who were totally immobile. We considered adequate preventive fall care to have been provided if each of these had been met for patients identified at risk for falls (Fig. 2) (Dutch Institute for Healthcare Improvement [CBO], 2004).

\subsection{Data collection}

Trained independent research assistants collected the data in: (1) a weekly visit, and (2) by three additional observations on every ward.

During the weekly visits, we collected data from the patient files and we observed the patients for the presence of preventive measures (Fig. 2).

Through additional observations, we collected information on applied preventive care measures (Fig. 2). We performed the additional observations for at least five consecutive hours in a random sample of at least five patients per ward who participated in the study.

\subsection{Statistical analysis}

The preventive care given was calculated for each adverse event separately, and only for patients who were considered to be at risk for that particular adverse event. The results for hospitals and nursing homes were analysed separately, as patient characteristics and length of stay differed.
Pressure Ulcers

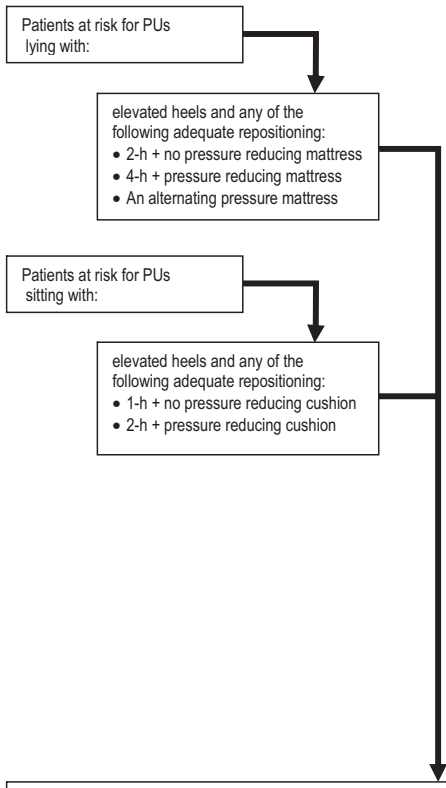

Adequate preventive care pressure ulcers
Urinary tract infections

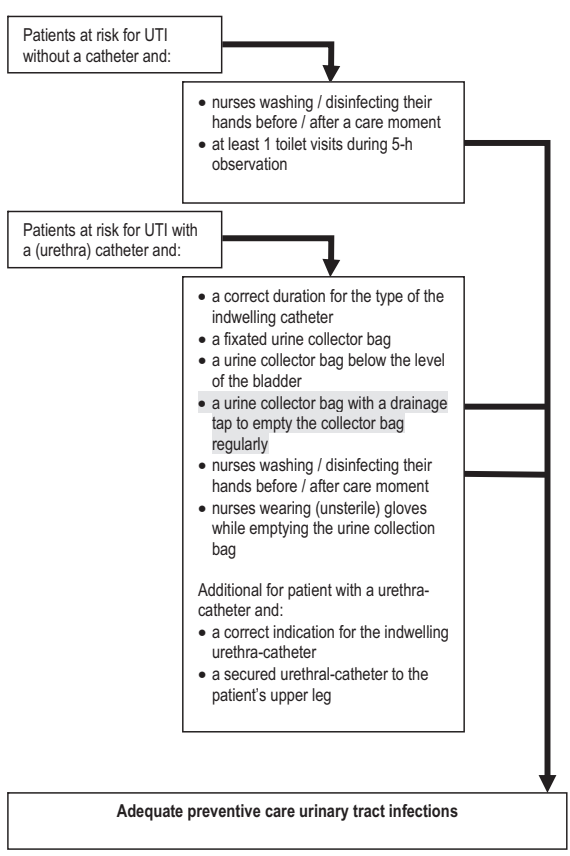

Fig. 2. Adequate preventive care consists of.

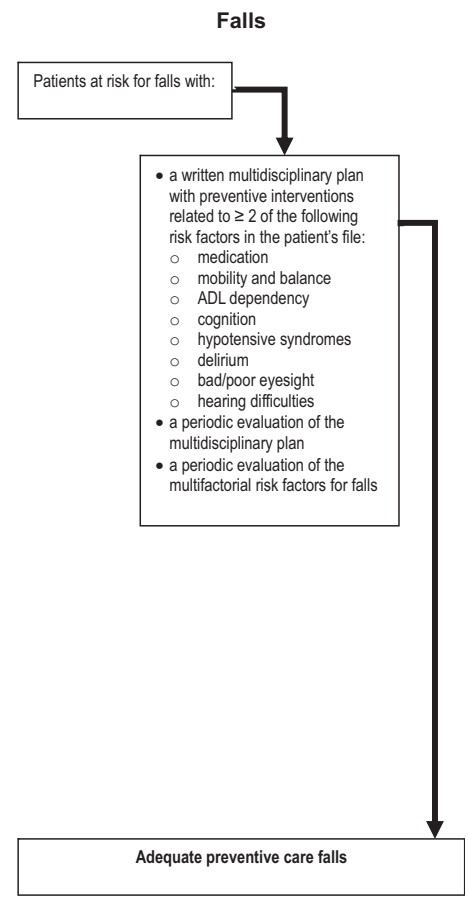


The results of this study were clustered to ward level, so we used random effects analyses with ward as random factor. Group, institution and the baseline results of the ward were fixed covariates. To analyse the difference in preventive care with respect to falls, we calculated the odds ratio, using a logistic model. For the other process measures, odds ratios were less appropriate, because the incidences were above $20 \%$, which makes odds ratios difficult to interpret. As a result, we were more interested in absolute differences, so we used a generalised linear model with Bernouilli distribution and linear link function. This linear analysis yielded a mean percentage that reflected the differences in mean percentage of preventive care between the intervention and the usual care group at follow-up. Ninety-five percent confidence intervals were calculated and results were considered significant if the confidence interval did not include unity.

\section{Results}

The characteristics of the patients included in the intervention and the usual care group at baseline and follow-up have been described in Part I of this study (Van
Gaal et al., 2011). To understand this article, we present an extended version of the description of patient characteristics in Table 1.

\subsection{Preventive care in hospitals}

Pressure ulcers: $49 \%$ of the hospital patients in the intervention group and $52 \%$ of the patients in the usual care group were at risk for pressure ulcers (Table 1). $98 \%$ of these patients were in bed or in a chair at the time of the visit in both the intervention and the usual care group. In both groups, $27 \%$ of the patients at risk received adequate preventive care, i.e. they had elevated heels while sitting on a chair or lying in bed and received adequate repositioning as well (Table 2 ). No statistically significant difference in patients at risk receiving adequate preventive care was found between the intervention and the usual care group (estimate $=6 \%, \mathrm{CI}:-7-19$ ) .

Urinary tract infections: $44 \%$ of the hospital patients in the intervention group and $54 \%$ of the patients in the usual care group were at risk for urinary tract infections (Table 1). $38 \%$ of these patients in the intervention group and $47 \%$ of these patients in the usual care group received adequate

Table 1

Characteristics of the patients in Part I of this study.

\begin{tabular}{|c|c|c|c|c|}
\hline \multirow[t]{2}{*}{ Hospitals } & \multicolumn{2}{|l|}{ Baseline } & \multicolumn{2}{|l|}{ Follow-up } \\
\hline & INT & UC & INT & UC \\
\hline$N$ & 346 & 341 & 1081 & 1120 \\
\hline Surgical patients & 256 & 255 & 825 & 789 \\
\hline Internal medicine patients & 90 & 86 & 256 & 331 \\
\hline Age in years (mean (SD)) & $66(14.5)$ & $64(16.9)$ & $66(14.7)$ & $67(16.1)$ \\
\hline Female & $184(53.2)$ & $204(59.8)$ & $570(52.7)$ & $646(57.7)$ \\
\hline Total visits & 842 & 875 & 2657 & 2902 \\
\hline Patient weeks & 496 & 534 & 1576 & 1782 \\
\hline Surgical: patient weeks & 344 & 374 & 1074 & 1231 \\
\hline Internal medicine: patient weeks & 152 & 160 & 502 & 551 \\
\hline Median admitted weeks (interquartile range) & $1(1-2)$ & $1(1-2)$ & $1(1-2)$ & $1(1-2)$ \\
\hline Patients at risk for PUs ${ }^{b}$ & 46 & 50 & 49 & 52 \\
\hline Patients at risk for UTIs ${ }^{b}$ & 44 & 53 & 44 & 54 \\
\hline Patients at risk for falls ${ }^{\mathrm{b}}$ & 15 & 23 & 16 & 22 \\
\hline Observed patients ${ }^{\mathrm{a}}$ & 77 & 70 & 100 & 109 \\
\hline Mean observed hours/day ${ }^{\mathrm{a}}$ & $6(1.3)$ & $6(1.1)$ & $4.9(0.6)$ & $4.7(0.6)$ \\
\hline \multirow[t]{2}{*}{ Nursing homes } & \multicolumn{2}{|l|}{ Baseline } & \multicolumn{2}{|l|}{ Follow-up } \\
\hline & INT & UC & INT & UC \\
\hline$N$ & 114 & 127 & 196 & 196 \\
\hline Physically impaired patients & 64 & 100 & 64 & 132 \\
\hline Rehabilitation patients & 50 & 27 & 132 & 64 \\
\hline Age in years (mean (SD)) & $78(9.9)$ & $78(11.7)$ & $80(10.9)$ & $79(10.5)$ \\
\hline Female & $70(61.4)$ & $89(66.0)$ & $131(66.8)$ & $126(64.3)$ \\
\hline Total visits & 1047 & 1185 & 2950 & 3241 \\
\hline Patient weeks & 933 & 1058 & 2754 & 3045 \\
\hline Physically impaired: patient weeks & 593 & 860 & 1533 & 2478 \\
\hline Rehabilitation: patient weeks & 340 & 198 & 1221 & 567 \\
\hline Median patient weeks (interquartile range) & $5(3-8)$ & $5(3-8)$ & $10(4-9)$ & $11(5-20)$ \\
\hline Patients at risk for PUs ${ }^{\mathrm{b}}$ & 64 & 58 & 47 & 52 \\
\hline Patients at risk for UTIs ${ }^{\mathrm{b}}$ & 100 & 100 & 100 & 100 \\
\hline Patients at risk for falls ${ }^{\mathrm{b}}$ & 68 & 65 & 78 & 52 \\
\hline Observed patients ${ }^{\mathrm{a}}$ & 89 & 88 & 151 & 148 \\
\hline Mean observed hours/day ${ }^{a}$ & $5.6(0.7)$ & $5.4(0.5)$ & $5.4(0.6)$ & $5.4(0.5)$ \\
\hline
\end{tabular}

Values represent numbers (\%), unless stated otherwise. INT = intervention group, UC=usual care group, PUs = pressure ulcers, UTIs $=$ urinary tract infections.

a Number of patients with mean observed hours per day during additional observations.

b Values represent \%. 
Table 2

Adequate preventive care given to patients at risk in hospitals.

\begin{tabular}{|c|c|c|c|c|}
\hline \multirow[t]{2}{*}{ Hospitals } & \multicolumn{2}{|c|}{ Baseline } & \multicolumn{2}{|c|}{ Follow-up } \\
\hline & INT & UC & INT & UC \\
\hline$N$ & 346 & 341 & 1081 & 1120 \\
\hline \multicolumn{5}{|l|}{ Pressure ulcers } \\
\hline \multicolumn{5}{|l|}{ Patients at risk: } \\
\hline \multicolumn{5}{|l|}{ with pressure reducing material: } \\
\hline Pressure reducing cushion & $1 \%$ & $2 \%$ & $2 \%$ & $2 \%$ \\
\hline Pressure reducing mattress & $97 \%$ & $97 \%$ & $86 \%$ & $98 \%$ \\
\hline Alternating mattress & $2 \%$ & $3 \%$ & $1 \%$ & $1 \%$ \\
\hline Sitting or lying with elevated heels & $35 \%$ & $40 \%$ & $29 \%$ & $40 \%$ \\
\hline Sitting or lying with elevated heels and adequate repositioning ${ }^{a}$ & $31 \%$ & $36 \%$ & $27 \%$ & $27 \%$ \\
\hline \multicolumn{5}{|l|}{ Urinary tract infections } \\
\hline Patients at risk without a catheter and: & $59 \%$ & $44 \%$ & $52 \%$ & $66 \%$ \\
\hline \multicolumn{5}{|l|}{ nurses' hand hygiene } \\
\hline At least 1 toilet visit during 5 -h observation & $61 \%$ & $44 \%$ & $33 \%$ & $33 \%$ \\
\hline Patients at risk with a catheter and: & $24 \%$ & $22 \%$ & $35 \%$ & $32 \%$ \\
\hline Nurses' hand hygiene & $56 \%$ & $50 \%$ & $53 \%$ & $66 \%$ \\
\hline A correct duration of the use of an indwelling catheter in conformity with the type of catheter & $44 \%$ & $64 \%$ & $51 \%$ & $58 \%$ \\
\hline A fixated urine collector bag & $86 \%$ & $85 \%$ & $84 \%$ & $90 \%$ \\
\hline A urine collector bag with a drainage tap to empty the collector bag regularly & $61 \%$ & $57 \%$ & $75 \%$ & $80 \%$ \\
\hline A urine collector bag below the level of the bladder & $91 \%$ & $84 \%$ & $88 \%$ & $92 \%$ \\
\hline Nurses wearing (unsterile) gloves while emptying the urine collector bag & $39 \%$ & $64 \%$ & $85 \%$ & $61 \%$ \\
\hline Patients with a urethra-catheter and: & $83 \%$ & 95 & $75 \%$ & $95 \%$ \\
\hline A secured urethra-catheter to patient's upper leg & $18 \%$ & $29 \%$ & $17 \%$ & $31 \%$ \\
\hline A correct indication for the indwelling urethra-catheter & $74 \%$ & $71 \%$ & $61 \%$ & $65 \%$ \\
\hline Overall: patients with and without a catheter and with all above-mentioned preventive measures ${ }^{\mathrm{a}}$ & $53 \%$ & $42 \%$ & $38 \%$ & $47 \%$ \\
\hline \multicolumn{5}{|l|}{ Falls } \\
\hline Patients at risk with: & $1 \%$ & 0 & $4 \%$ & $3 \%$ \\
\hline \multicolumn{5}{|l|}{ A written multidisciplinary plan } \\
\hline And preventive activities related to $\geq 2$ risk factors ${ }^{a}$ & 0 & 0 & $1 \%$ & 0 \\
\hline And periodic evaluation of the multidisciplinary plan & 0 & 0 & $1 \%$ & 0 \\
\hline And periodic evaluation of the risk factors for falls & 0 & 0 & $1 \%$ & $<1 \%$ \\
\hline
\end{tabular}

Values represent \%, unless stated otherwise.

a The analysis combined 'adequate preventive care'.

preventive care. Statistically significantly fewer patients at risk in the intervention group received adequate preventive care (estimate $=19 \%$, CI: 17-21).

Falls: $16 \%$ of the hospital patients in the intervention group and $22 \%$ of the patients in the usual care group were at risk for falls (Table 1 ). In the intervention group, only $1 \%$ of these patients had a written multidisciplinary plan with multifactorial preventive interventions, specifically addressed at the prevention of falls. These multidisciplinary plans and the risk factors for falls were evaluated on admission. In the usual care group, no patients at risk had a written multidisciplinary plan with multifactorial preventive interventions, specifically addressed at the prevention of falls. The numbers were too low for statistical analysis, but it seems obvious that there was no difference between the intervention and the usual care group in adequate preventive care given.

\subsection{Preventive care in nursing homes}

Pressure ulcers: $58 \%$ of the nursing home patients in the intervention group and $71 \%$ of the patients in the usual care group were at risk for pressure ulcers (Table 1 ). In the intervention group, $99 \%$ of patients and all patients in the usual care group were in bed or in a chair at the time of the visit. In the intervention group, $19 \%$ of the patients at risk received adequate preventive care, i.e. they had elevated heels while sitting on a chair or lying in bed and received adequate repositioning as well, compared to $13 \%$ in the usual care group (Table 3). Statistically, no difference in patients at risk who received adequate preventive care was found between the intervention and the usual care group (estimate $=4 \%$, CI: $-5-13$ ).

Urinary tract infections: All nursing home patients were at risk for urinary tract infections in both groups (Table 3 ). $43 \%$ of these patients in the intervention group received adequate preventive care compared to $41 \%$ in the usual care group. Statistically, no difference in patients at risk receiving adequate preventive care was found between the intervention and the usual care group (estimate $=6 \%, \mathrm{CI}$ : -13-26).

Falls: $78 \%$ of the nursing home patients in the intervention group and $52 \%$ of the patients in the usual care group were at risk for falls (Table 3). In the intervention group, $22 \%$ of these patients at risk had a written multidisciplinary plan with multifactorial preventive interventions specifically addressing the prevention of falls. One percent of these multidisciplinary plans was evaluated periodically. The risk factors for falls were also evaluated in $1 \%$ on admission. Thus overall $1 \%$ of the patients received adequate preventive care. In the usual care group, $3 \%$ of the patients at risk had a written multidisciplinary plan with multifactorial preventive interventions, specifically addressed at the prevention of falls. In $1 \%$ of the patients at risk, the multidisciplinary plan was evaluated and in less than $1 \%$ the risk factors for falls were evaluated. Thus overall less than $1 \%$ of the patients received adequate preventive care. The percentage of 
Table 3

Adequate preventive care given to patients at risk in nursing homes.

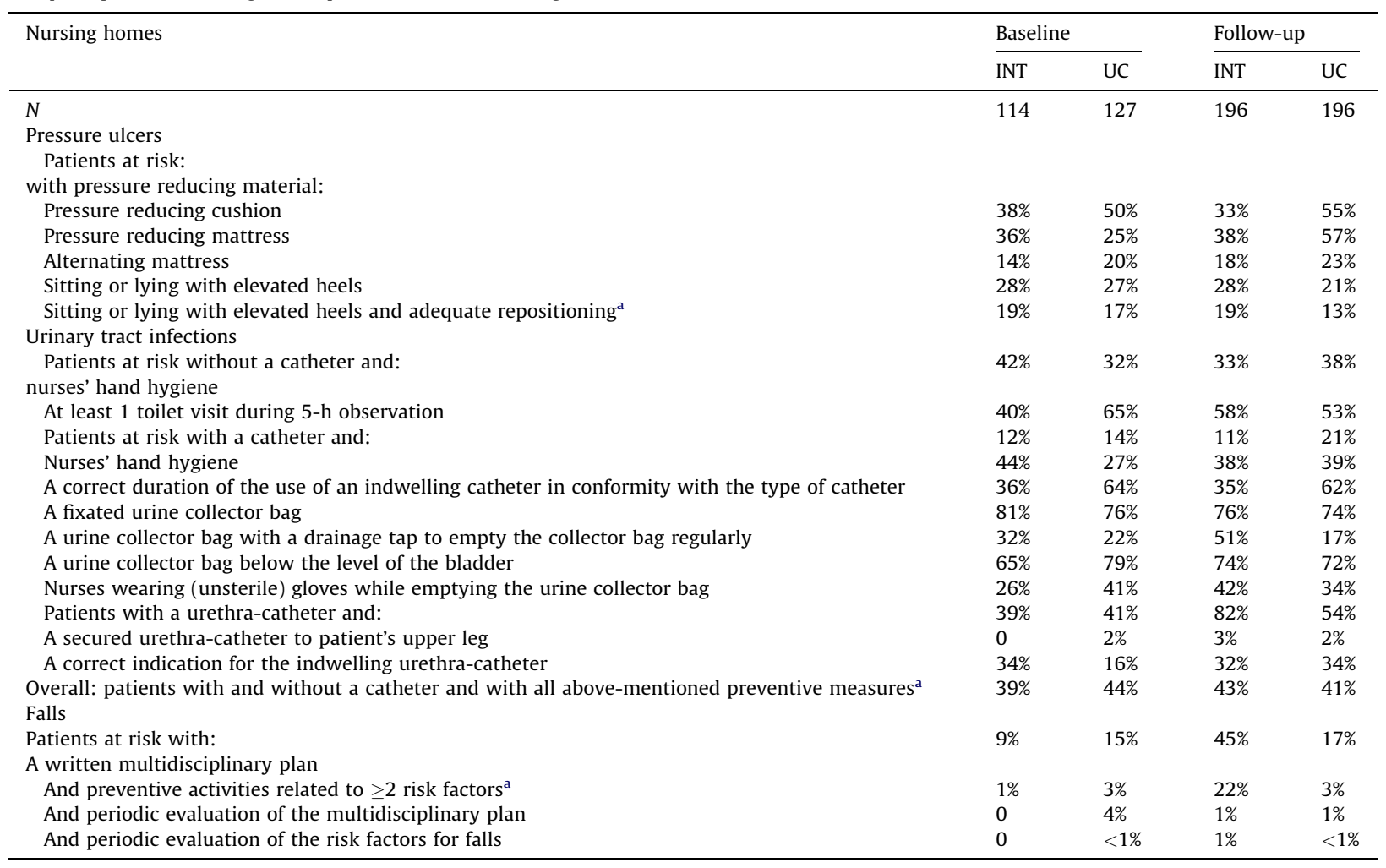

Values represent \%, unless stated otherwise.

a The analysis combined 'adequate preventive care'.

patients receiving adequate preventive care was too low for statistical analysis. Instead, we analysed the difference in patients with a written multidisciplinary plan with multifactorial preventive interventions between the intervention and the usual care group. The results showed that in the intervention group more patients at risk for falls had a multidisciplinary plan with multifactorial preventive interventions (22\%) compared to the usual care group (3\%) $P<0.01$.

\section{Discussion and conclusion}

This study aimed to test if the effect on the main outcome - incidence of three adverse events - coincided with a favourable effect on the process measures adequate preventive care - for patients at risk for these adverse events. We found that the percentage of patients at risk for pressure ulcers who received preventive measures did not differ between the intervention and the usual care group, in both hospitals and nursing homes. For urinary tract infections, we only found a difference in hospitals, but this difference was in favour of the usual care group. For falls, there was no difference between the intervention and the usual care group, in hospitals or in nursing homes. In nursing homes, more patients at risk for falls in the intervention group had a written multidisciplinary plan with multifactorial preventive interventions, specifically addressed at the prevention of falls, but not enough patients had an evaluated multidisciplinary plan or had an evaluation of the risk factors for falls, which are both essential in adequate preventive care for falls. These findings are not in line with the decrease in the adverse events we described earlier (Part I). The idea behind the patient safety programme was that it is a comprehensive programme for the implementation of multiple guidelines, which is applicable for many guidelines in health care, particularly by the structural approach of each topic and the computerised programme that gave timely feedback on the indicators (Part I). The results of this study showed that more research on the effectiveness of this patient safety programme is needed.

In this study, we measured both outcome and process indicators. There is an ongoing discussion about whether processes or outcomes should be measured in quality assessment (Braspenning et al., 2005). An advantage of outcome measures is that they reflect all aspects of the process of care and not simply those that are measurable or measured (Mant, 2001). In Part I of this study, we reported the results of the patient safety programme on the incidence of the three adverse events. We found $43 \%$ and $33 \%$ fewer adverse events for patients in the intervention group in hospitals and nursing homes, respectively. Differences in outcome cannot simply be explained by differences in care. They can be explained by case mix, differences in data collection methods, chance, or differences in quality of care (Mant, 2001). An outcome 
indicator will not give detailed insight into the differences in care. Therefore, as described in Part I, we chose an outcome that is more sensitive to differences in preventive care: the incidence of adverse events (Van Gaal et al., 2011).

An advantage of process indicators is that they are more sensitive to differences in the quality of care than outcome measures (Mant, 2001). Process indicators are easier to formulate and are less affected by confounders, but their relationship with specific patient outcomes may be less certain (Braspenning et al., 2005). Therefore, we did not only measure process indicators, but outcome indicators as well.

In this study, we adjusted for the differences in type of patient, we analysed the results separately for hospitals and nursing homes and stratified the randomisation for institute and ward. Additionally, we standardised the measurements and the study was powered on the outcome indicator. By doing this, we assumed that the positive results on the outcome (Part I) would be related to the differences in the quality of care and we expected to find positive results on the preventive care. Surprisingly, we did not find more prevention. How do we match the positive results described in Part I of this study to the results presented in this article?

A first explanation could be found in the feedback of the guideline based outcome and process indicators used in the computerised registration and feedback system of the patient safety programme. Per topic we developed outcome and process indicators, which were meant to give insight into the quality of care of the nurses on the intervention wards regarding the three adverse events. However, the feedback on the process indicators in our patient safety programme may not have been sufficient. The feedback on the process indicators differed from the outcome indicators in two ways. First, we developed more outcome indicators and only one combined process indicator per topic and second, the nurses received daily feedback on the outcome indicators while the feedback on the process indicators was only provided once a week. As a result of that, nurses only 'saw' how they provided preventive care once a week but they immediately (the next morning) 'saw' whether patients on the ward developed (incidence) or had an adverse event (prevalence). As a result of this low frequency of feedback, nurses had less opportunity to act. Furthermore, the feedback for each of the three topics on the process indicators was summarised into a single adequate prevention score' indicator per topic. By doing this, nurses could monitor preventive care rather roughly but did not get a detailed insight into their preventive care performance. For instance, if patients did not have a repositioning scheme (and no alternating pressure mattress), but received all the other preventive activities, this was not registered as good preventive care. As a result, nurses were not able to see which activity they had to give more attention to, e.g. repositioning. Nurses only saw - in a graphic - the percentage of patients who received "adequate" preventive care. In future, this can be improved by giving feedback on the several process indicators per topic, so that professionals will gain an insight into the preventive activities given and the preventive activities withheld.

Another possible explanation concerns some methodological considerations and the data collection in this study. We measured the combined process indicator per topic and therefore used a rigorous standard of what we considered as adequate preventive care. Only patients who met the combination of preventive activities given (Fig. 2) at every observation moment were registered as receiving "adequate" preventive care. As a result, quite a few preventive activities were not registered as "adequate" preventive care, because they had not been combined with other preventive activities. It is questionable whether it is necessary to combine the activities in order to be effective in preventing the specific adverse events, and if all these preventive activities are necessary all the time. Perhaps it suffices to receive $80 \%$ of all the activities or to receive the preventive activities in four out of five observation moments and not five out of five, as we have performed in this study. By using this rigorous standard, we probably registered a lot of preventive activities as inadequate preventive care and therefore missed them in our results.

A further point is the identification of patients at risk for adverse events, i.e. those who should receive preventive care. We used recommended risk assessment scales for pressure ulcers and falls (Braden and Bergstrom, 1994; Oliver et al., 1997; Schoonhoven et al., 2006). Even though we used accepted and validated risk assessment scales, we acknowledge that the currently available scales for pressure ulcers and falls have their limitations. The risk assessment scales are known to classify patients incorrectly into both the 'at risk' and 'not at risk' groups (Defloor and Grypdonck, 2004; Schoonhoven et al., 2002; Oliver et al., 2008). In this study, we used a risk assessment scale for pressure ulcers in combination with the Braden subscales 'mobility' (score less than 3 ) and 'activity' (score less than 3), because immobile (Braden subscale less than 3 ) and/or inactive patients (Braden subscale less than 3 ) are unable to move sufficiently of their own accord and are therefore at risk for pressure ulcers. The risk assessment scales used did not classify all the immobile or inactive patients as being 'at risk'. Therefore, we combined the risk assessment scales used in hospitals and nursing homes with the Braden subscales 'mobility' and 'activity'. As a result of this, we may have overestimated the patients at risk for pressure ulcers and thus the patients who should receive prevention.

Furthermore, the nurses on the wards were trained in assessing the patients at risk with a risk assessment tool (PrePURSE and STRATIFY in hospitals and Braden in nursing homes), in combination with their clinical judgement. As a result, nurses in daily practice may have adjusted the classification of the risk status of the patients on the basis of their clinical judgement. Therefore, nurses probably will not give preventive care to every patient at risk according to a risk assessment scale.

An additional explanation concerns the data collection of this study and the patient files which have been used to collect data. They have been found to notoriously underreport the care given (Polit and Beck, 2004). Underreporting may have occurred in the prevention given on 
falls, as fall prevention prescribes a written multidisciplinary plan, which should be part of the patient file. Especially in hospitals where the patient turnover is high, we did not often find such a written multidisciplinary plan in the patient files. To limit underreporting, we combined two data collection methods. Apart from the data from the patient files, we collected data by observing the preventive care given to the patients at risk. If the data were only collected during the weekly visits, it would be impossible to measure typical preventive interventions, e.g. adequate repositioning for patients at risk for pressure ulcers or hand hygiene for patients at risk for urinary tract infections. Therefore, three observations were performed on every ward in addition to the weekly visits. By using combined data collection methods, we obtained a better impression of the preventive care given and tried to limit underreporting of data.

A last point is that preventive care is a continuous process: $24 \mathrm{~h}$ a day and 7 days a week. Despite the combined data collection, we were only able to give a random indication of the continuous process of preventive care given, which is a limited impression and not the continuous process.

On the basis of this study we come to a few recommendations. The first concerns the development of process indicators. Process indicators can be used to measure quality improvement, but they should be tested for their validity, reliability, as well as their sensitivity to change. A second suggestion concerns monitoring quality improvement by using process indicators. To gain insight into the process of guideline based preventive care, it is essential to develop several process indicators reflecting the essential guideline based recommendations. Finally, collecting data on the preventive care given is not easy, because it is a continuous complex process and it is impossible to measure such care $24 \mathrm{~h}$ a day and seven days a week. To obtain an accurate impression of the preventive care, we recommend collecting this kind of data through frequent observations.

In conclusion, though the SAFE OR SORRY? programme effectively reduced the number of adverse events, an increase in preventive care given to patients at risk was not demonstrated. These results emphasise the difficulties in measuring the compliance to guidelines. More research is needed to explore the possibilities of measuring the implementation of multiple guidelines by using process indicators.

\section{Conflict of interest}

The authors declare that they have no competing interests.

\section{Funding}

The Netherlands Organisation for Health Research and Development (ZonMw) funded and approved the design of this study [ID: 54010002]. This funding organisation did not have any role in the selection of the hospitals or nursing homes; the collection, analysis and interpretation of the data; the writing of the report or the decision to submit this article for publication.

\section{Ethical approval}

The local Medical Ethics Committee assessed the study and waived the need for complete evaluation of the study. Ref. nr: CMO nr: 2005/121.

\section{Authors' contributions}

BvG wrote the article, developed the patient safety programme, coordinated the study, prepared instruments for the study, and collected and analysed the data. LS wrote the article, supervised the study, developed the design of this study and the patient safety programme, and was involved in the development of the instruments for the study. JM developed the design of this study and the patient safety programme, was involved in the development of the instruments for the study, and revised the article. GB is a statistician and has been involved in the design of the study, supervised the analyses of the study and revised the article. RK developed the design of this study and the patient safety programme, was involved in the development of the instruments for the study, and revised the article. TvA was the general supervisor of the study, developed the design of this study and the patient safety programme, was involved in the development of the instruments for the study, and revised the article.

\section{References}

Braden, B.J., Bergstrom, N., 1994. Predictive validity of the Braden Scale for pressure sore risk in a nursing home population. Res. Nurs. Health 17 (6), 459-470.

Braspenning, J., Campbell, S., Grol, R., 2005. Measuring changes in patient care: development and use of indicators. In: Grol, R., Wensing, M., Eccles, M. (Eds.), Improving Patient Care. Elsevier, Oxford, pp. 222-234

Defloor, T., Grypdonck, M.F., 2004. Validation of pressure ulcer risk assessment scales: a critique. J. Adv. Nurs. 48 (6), 613-621.

Defloor, T., Herremans, A., Grypdonck, M.H., De Schuijmer, J.D., Paquay, L., Schoonhoven, L., Vanderwee, K., Bours, G., Cuyvers, A., De Laat, E., Feyaerts, S., Demaiter, G., Haalboom, J., Halfens, R., Heyman, H., Van Kol, E., Weststraete, J., 2005. Belgium Guideline Prevention of Pressure Ulcers. Academia Press, Gent.

Dutch Association of Nursing Home Physicians (NVVA), 2003. Tripartite Multidisciplinary Guideline: Collaboration and Logistic Process of Pressure Ulcers. Beroepsvereniging van verpleeghuisartsen en geriaters (NVVA), Utrecht.

Dutch Association of Nursing Home Physicians (NVVA), 2006. Guideline Urinary Tract Infections. Beroepsvereniging van verpleeghuisartsen en geriaters (NVVA), Utrecht.

Dutch Institute for Healthcare Improvement [CBO], 2002. Second revision pressure ulcers. Downloaded May 2005; available from. Dutch Institute for Healthcare Improvement [CBO], only in Dutch http://www.cbo.nl/product/richtlijnen/folder20021023121843/ decubitus2002.pdf?.

Dutch Institute for Healthcare Improvement [CBO], 2004. Guidelines 'Fall Prevention in the Elderly'. Van Zuiden Communications BV, Alphen aan den Rijn.

Dutch Working Party on Infection Prevention (WIP), 2005. Prevention of Infection as a Result of Urinary Catheterisation via the Urethra. Leiden University Medical Centre, Leiden.

Mant, J., 2001. Process versus outcome indicators in the assessment of quality of health care. Int. J. Qual. Health Care 13 (6), 475-480.

Oliver, D., Britton, M., Seed, P., Martin, F.C., Hopper, A.H., 1997. Development and evaluation of evidence based risk assessment tool (STRATIFY) to predict which elderly inpatients will fall: case-control and cohort studies. BMJ 315 (7115), 1049-1053. 
Oliver, D., Papaioannou, A., Giangregorio, L., Thabane, L., Reizgys, K., Foster, G., 2008. A systematic review and meta-analysis of studies using the STRATIFY tool for prediction of falls in hospital patients: how well does it work? Age Ageing 37 (6), 621-627.

Polit, D.F., Beck, C.T., 2004. Nursing Research: Principles and Methods. Lippincott Williams \& Wilkins, Philadelphia.

Schoonhoven, L., Haalboom, J.R., Bousema, M.T., Algra, A., Grobbee, D.E., Grypdonck, M.H., Buskens, E., 2002. Prospective cohort study of routine use of risk assessment scales for prediction of pressure ulcers. BMJ 325 (7368), 797.
Schoonhoven, L., Grobbee, D.E., Donders, A.R., Algra, A., Grypdonck, M.H., Bousema, M.T., Schrijvers, A.J., Buskens, E., 2006. Prediction of pressure ulcer development in hospitalized patients: a. tool for risk assessment. Qual. Saf. Health Care 15 (1), 65-70.

Van Gaal, B.G.I., Schoonhoven, L., Mintjes, J.A.J., Borm, G.F., Hulscher, M.E.J.L., Defloor, T., Habets, H., Voss, A., Vloet, L.C.M., Koopmans, R.T.C.M., Van Achterberg, T., 2011. Fewer adverse events as a result of the SAFE or SORRY? programme in hospitals and nursing homes. Part I: Primary outcome of a cluster randomised trial. Int. J. Nurs. Stud. 48 (9), 1040-1048. 